\title{
Design of a Sea Water Distiller Using Thermo-Solar Energy
}

\author{
Cuauhtémoc Pozos Vázquez, PhD \\ Victor Daniel Acuña Díaz \\ Juan Pablo Torres Cruz. \\ Instituto de Estudios Superiores de Tamaulipas (IEST), \\ Altamira, Tamaulipas, México
}

Doi: 10.19044/esj.2018.v14n9p60 URL:http://dx.doi.org/10.19044/esj.2018.v14n9p60

\begin{abstract}
There are different technologies for the desalination of seawater, such as reverse osmosis and conventional distillation based on electricity and fuels. In this last one, it is worth highlighting the distillation using renewable energies in which, during their operation, greenhouse gases are not emitted. The present study aims to obtain potable water by distillation of seawater using a prototype that reflects and concentrates the solar energy towards a container of salt water using a system of solar collectors of the parabolic plate type. A salt removal of $99 \%$ was obtained, which was verified with the conductivity $(281.33 \mu \mathrm{S} / \mathrm{cm})$, salinity $(0.1 \%)$, and total dissolved solids $(135.2 \mathrm{mg} / \mathrm{L})$ determinations. Based on these results, it is proposed that any population with access to the sea and good average annual solar radiation could use the proposed prototype.
\end{abstract}

Keywords: Solar thermal collector, desalination, solar water distiller

\section{Resumen}

Para la desalinización de agua de mar existen diferentes tecnologías tales como la osmosis inversa y la destilación convencional a base de electricidad y de combustibles. En este última cabe resaltar la destilación mediante el uso de las energías renovables en la cual para su funcionamiento no se emiten gases de efecto invernadero. En este estudio el objetivo es obtener agua potable mediante la destilación del agua de mar utilizando para ella un prototipo que refleje y concentre la energía solar hacia un contenedor de agua salada mediante un sistema de captadores solares de tipo plato parabólico. Se obtuvo una remoción de sales del $99 \%$, lo cual se constato con las determinaciones de conductividad $(281.33 \mathrm{mS} / \mathrm{cm})$, salinidad $(0.1 \%)$, y sólidos totales disueltos $(135.2 \mathrm{mg} / \mathrm{L})$. En base a los resultados obtenidos se propone 
que cualquier población con acceso al mar y buena radiación solar promedio anual podría utilizar el prototipo propuesto.

Palabras-claves: Lirio acuático, biosorción, biomateriales

\section{Introducción}

Es un hecho que las fuentes de agua cada vez son más escasas y más difíciles de tratar por su alto nivel de contaminación, haciendo cada vez más costoso el proceso de potabilización y poniendo en riesgo a quienes consumen de los mantos acuíferos de forma directa. La UNESCO considera que a mediados del siglo XXI la población global llegará a los 12,000 millones de habitantes previstos por lo que la demanda de agua se duplicará y las reservas llegarán a su límite, por ello, es necesario pensar en alternativas que solucionen tan creciente problemática.

Los oceanos y los mares son las reservas más grandes de agua, sin embargo debido a sus altas concentraciones de sal no pueden ser directamente usadas para consumo humano, irrigación e industria. Por lo tanto, la desalinización se ha convertido en una técnica importante para la obtención de agua potable en muchos países y muchas investigaciones han sido orientadas a minimizar el costo de este proceso. Entre esos métodos la destilación aparece como una de las mejores practicas y de las más económicas para la obtención de agua potable a partir de agua de mar (Saidur, Elcevvadi, Mekhilef, Safari, \& Mohammed, 2011).

Una de las propuestas son los destiladores solares, que pueden ser construidos de muchas formas y con diferentes materiales, así como destinados a diferentes usos, estos pueden construirse fijos o portátiles, así como instalarse permanentemente o de forma transitoria, algunos tipos conocidos son (Al-Hayek \& Badran, 2004):

- Destilador solar de dos vertientes (tipo invernadero simétrico): Este modelo consta de un "tejado" dos aguas de material transparente. Las gotas de agua que se han condensado en el panel transparente se deslizan por los lados y precipitan a un depósito situado bajo la bandeja donde se dispone el agua destilada. Desde el depósito de almacenamiento se extrae el agua por medio de un grifo.

- Destilador solar de una vertiente (tipo invernadero asimétrico): Se trata de una caja cubierta por un cristal inclinado. La caja está dividida en dos compartimentos: uno con el fondo de color negro donde se coloca el agua a evaporar y que ocupa la mayor parte de la caja y el otro de menores dimensiones donde se recoge el agua destilada y que se encuentra en el lado de menor altura, asimismo sobre la pared interna del lado de mayor altura se coloca un espejo. 


\section{Objetivo general}

Diseñar un prototipo funcional, el cual emplee energía renovable para la obtención de agua desprovista de sales a partir de agua de mar.

\section{Objetivos específicos}

Monitorear las temperaturas alcanzadas durante el funcionamiento del prototipo durante el proceso de calentamiento producido por la radiación solar.

Verificar la calidad del agua desalinizada generada a través del prototipo mediante su análisis químico.

\section{Parte experimental}

Las partes que componen al prototipo se observan en la Figura 1. Primeramente se procedió a la fabricación de los captadores solares de tipo plato parabólico, hoy en día este tipo de captadores sirven para accionar un motor tipo Stirling colocado en el punto focal del disco paraboloide (Balado, 2011).

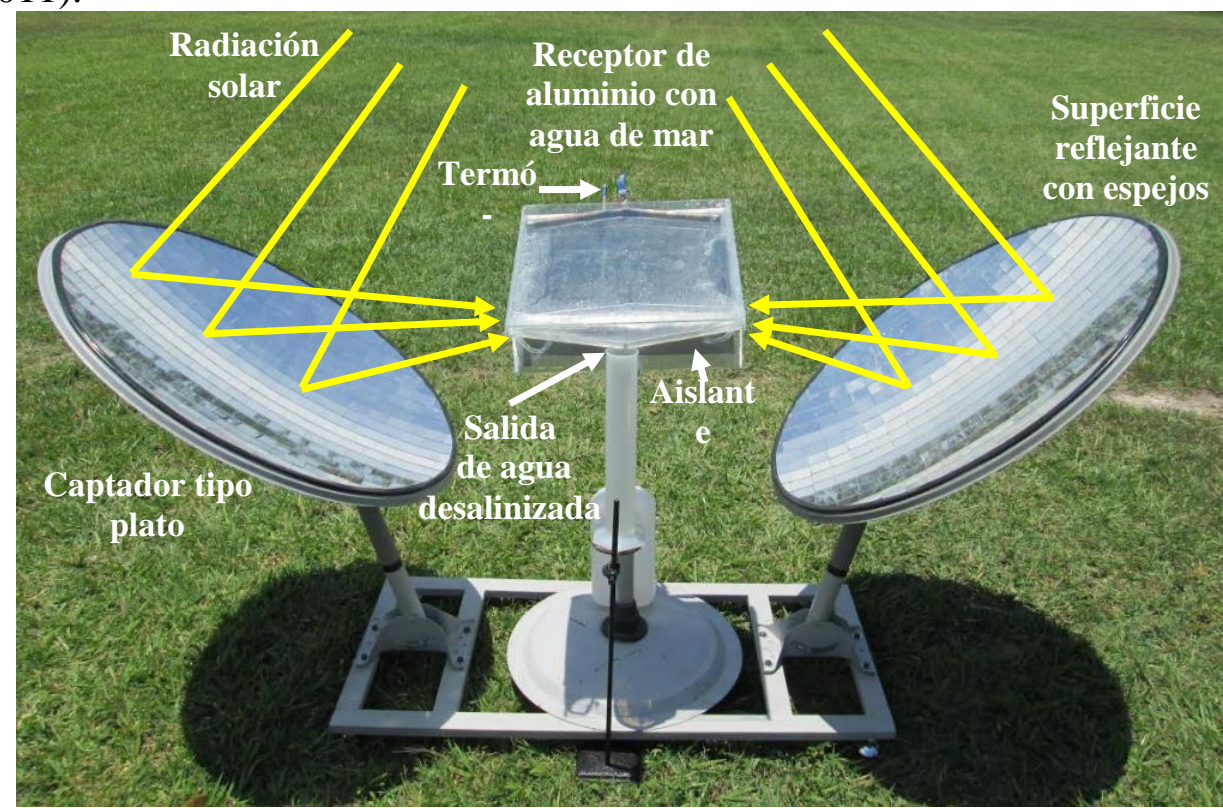

Figura 1. Esquema del montaje del prototipo

En este prototipo cada captador solar está provisto de 306 espejos de $4 \mathrm{x} 4 \mathrm{~cm}$ cada uno ensamblados sobre una antena de telecomunicaciones utilizando para ello silicona como adhesivo. Las dimensiones de cada antena son las siguientes: $82 \mathrm{~cm}$ de diámetro mayor y $76 \mathrm{~cm}$ de diámetro menor, así como una profundidad de $7 \mathrm{~cm}$.

Los rayos de luz solares son reflejados a partir de la superficie de cada captador y son concentrados en dos puntos focales $(50 \mathrm{~cm})$ localizados a la derecha e izquierda del receptor (partes laterales) que contiene el agua de mar, 
la cual fue muestreada de la Playa Miramar de Ciudad Madero, Tamaulipas. Como receptor se utilizó un contenedor de aluminio en forma de prisma seccionado por un plano oblicuo a la base rectangular de $30 \mathrm{~cm} \mathrm{x} 40 \mathrm{~cm}$.

Se utilizó lamina de aluminio ya que este metal es un buen conductor del calor con una conductividad térmica, $\mathrm{k}=237 \mathrm{~W} / \mathrm{m} .{ }^{\circ} \mathrm{C}$ y el espesor de la pared del receptor fue de $1 \mathrm{~mm}$. Las superficies laterales externas del receptor que reciben la radiación solar incidente (la temperatura fue medida con un Pirómetro modelo:ST652) se recubrieron con pintura negra (absortividad solar $=0.97)$ con la finalidad de mejorar la transferencia de calor hacia el receptor (Çengel, 2014).

Las partes anterior y posterior del receptor fueron recubiertas de un aislante térmico a base de fibra de vidrio para evitar las pérdidas de calor por convección debido a la interacción con el aire del medio ambiente. Se introdujo en el interior del receptor un tubo de cobre, el cual une las dos partes laterales desde la parte inferior del recipiente, ya que en la convección libre de líquidos el valor del coeficiente global de transferencia de calor $(h)$ está en el orden de $10-1000 \mathrm{~W} / \mathrm{m}^{2} .{ }^{\circ} \mathrm{C}$ y como el sistema está en reposo (desprovisto de agitación) este dispositivo facilitaría la transmisión del calor en el líquido.

La parte superior del receptor actua como condensador (Figura 2), la cual es un compartimiento rectangular de vidrio por donde entra agua de mar por su extremo superior para llenarlo (2a). Dicho compartimiento posee una inclinación con la finalidad de favorecer el escurrimiento sobre la superficie interna de su tapa inferior (2b) de las gotas condensadas del vapor de agua generado durante el proceso de calentamiento hacia la salida, en la cual se recupera el agua desalinizada. En el extremo inferior posee a cada lado dos conexiones de tubings de vidrio (2c) provistos de válvulas hacia el interior del receptor con la finalidad de alimentarlo cuando el nivel del líquido descienda.

Cabe remarcar que el agua proveniente del condensador esta precalentada debido al intercambio de calor que se efectuó con los vapores de agua generados, por tal motivo, no afectará de manera significativa el proceso de calentamiento en camparación con una alimentación de agua fresca (a temperatura ambiente) con la finalidad de obtener asi un funcionamiento de operación continuo del sistema. En la parte posterior del receptor se realizó una perforación para adaptar un termómetro con la finalidad de monitorear el incremento de temperatura del líquido. 

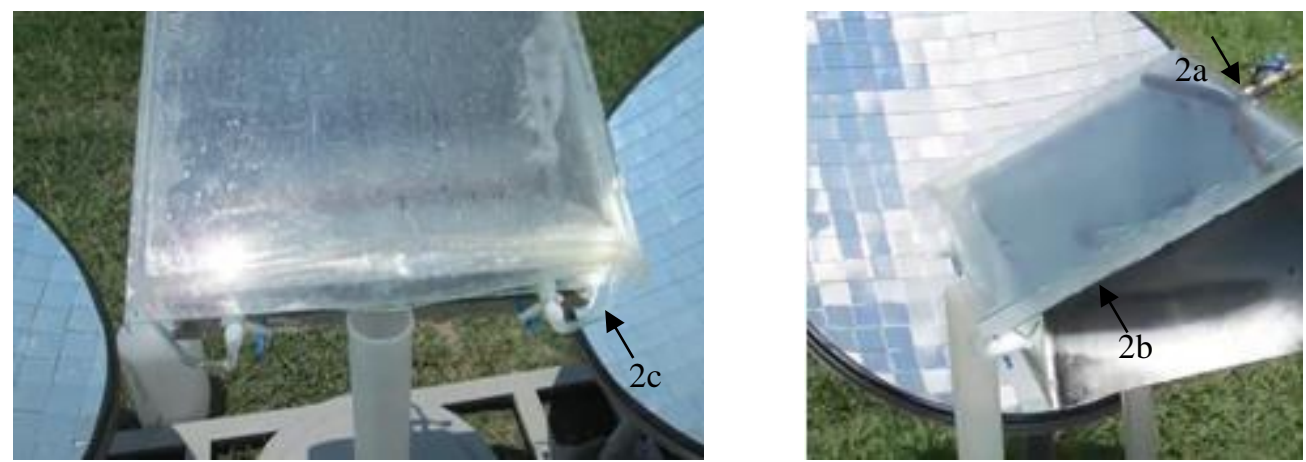

Figura 2. De izquierda a derecha: Vistas superior y lateral del receptor

El producto obtenido (condensado), el agua de mar (materia prima) y el agua desmineralizada (testigo o blanco) fueron analizados mediante la técnica de determinación de cloruros totales en aguas naturales, residuales y residuales tratadas conforme a la norma NMX-AA-073-SCFI-2011.

Entre las principales propiedades químicas del agua de mar se destaca la salinidad, la cual resulta de la combinación de las diferentes sales que se encuentran disueltas en el agua oceánica, siendo las principales los cloruros, carbonatos y sulfatos. Básicamente el mar es una solución acuosa de sales, entre estas, el cloruro de sodio $(\mathrm{NaCl})$ destaca por su cantidad, ya que constituye por sí sola el $80 \%$ de las sales.

Un alto contenido del anión cloruro puede dañar estructuras metálicas y evitar el crecimiento de plantas. Las altas concentraciones de cloruro en aguas cuando éstas son utilizadas para el riego en campos agrícolas deteriora, en forma importante la calidad del suelo. Por tal motivo, se eligió esta técnica para demostrar la calidad del agua obtenida mediante este nuevo artefacto.

\section{Procedimiento del análisis de cloruros}

1. Blanco. $30 \mathrm{~mL}$ de agua desmineralizada en matraz Erlenmeyer

2. Producto. $4 \mathrm{~mL}$ de agua destilada más $26 \mathrm{~mL}$ de agua desmineralizada en matraz Erlenmeyer.

3. Materia prima. $4 \mathrm{~mL}$ de agua de mar más $26 \mathrm{~mL}$ de agua desmineralizada en matraz Erlenmeyer.

4. $\mathrm{pH}$ de muestras. Inicialmente las 3 muestras contaban con un $\mathrm{pH}=6$. Se les añadió $1 \mathrm{~mL}$ de hidróxido de sodio $(\mathrm{NaOH}) \quad 0.1 \mathrm{~N}$ para incrementar su $\mathrm{pH}$ a 8 según la norma.

5. Indicador. Se les añadió a cada muestra 10 gotas de cromato de potasio $\left(\mathrm{K}_{2} \mathrm{CrO}_{4}\right)$.

6. Titulación: Uso de la solución de nitrato de plata $\left(\mathrm{AgNO}_{3}\right)$ 0.014N. En las inmediaciones del punto de equivalencia al agotarse el ión cloruro, empieza la precipitación del cromato. La formación del cromato de plata puede identificarse por el cambio de color de la disolución a 
anaranjado-rojizo y formación de un precipitado. En este momento se da por terminada la valoración.

Como comprobación de la remoción de sales efectuada en el proceso, se procedió a la determinación de la conductividad electrolítica mediante la norma NMX-AA-093-SCFI-2000, la cual esta basada en la detección de iones en las muestras.

\section{Procedimiento del análisis de conductividad electrolítica:}

1. Se verifica la operación del conductímetro sension5 marca HATCH midiendo una solución de conductividad conocida de $1.99 \mu \mathrm{s}$ ( $1 \mathrm{~g}$ $\mathrm{NaCl} / 1 \mathrm{~L} \mathrm{H}_{2} \mathrm{O}$ ) a temperatura ambiente.

2. Lavado del electrodo etre cada medición efectuada con agua desmineralizada de laboratorio.

3. Medición con agitación hasta llegar al punto estabilizado y efectuando por triplicado la lectura de cada muestra.

4. Utililizar las modalidades de lectura de salinidad y sólidos totales disueltos, permitidas por el equipo.

\section{Resultados y discusión}

La primera gota de destilado en el prototipo durante su operación apareció después de 40 minutos de haber iniciado la exposición del receptor (se le introdujó inicalmente 4L de agua de mar) a los rayos solares que fueron concentrados por los captadores solares emitiendo un foco que alcanzaba mediciones de hasta $148^{\circ} \mathrm{C}$ sobre cada superficie lateral externa. Una vez alcanzado el estado continuo de operación se obtiene un flujo volumétrico de $15 \mathrm{~mL} / \mathrm{hr}$ de destilado.



Gráfica 1. Variación de la temperatura del agua en el interior del recipiente en función de la hora del día en la que se realizó la exposición a la radiación solar.

En la gráfica 1 se observa que se alcanzaron temperaturas iguales o superiores a $70^{\circ} \mathrm{C}$ en el líquido en el intervalo de 14:10 - 16:10 horas en un 
día parcialmente soleado y el máximo de temperatura alcanzado por el prototipo fue de $77^{\circ} \mathrm{C}$ que corresponde a las 14:30 horas del 28 de junio del 2017 en la ciudad de Altamira, Tamaulipas. En base al mapa de irradiación solar $\left(\mathrm{kWh} / \mathrm{m}^{2}\right.$.dia) de México se pueden identificar zonas en las que hay mayor irradiación, resaltando entre ellas zonas costeras del Océano Pacífico $\left(5.8 \mathrm{kWh} / \mathrm{m}^{2}\right.$.dia), y por consecuencia se esperaría que este artefacto en dichas zonas alcanzará temperaturas mayores de operación.

Los resultados obtenidos del análisis de cloruros son los mostrados en la Tabla 1:

\begin{tabular}{|c|c|}
\hline Muestras & Volumen del titulante $\left(\mathrm{AgNO}_{3} 0.014 \mathrm{~N}\right)$ gastado, $\mathrm{mL}$ \\
\hline Blanco (agua desmineralizada) & 3 \\
\hline Producto (agua destilada) & 1.5 \\
\hline Materia prima (agua de mar) & 50 (formación de precipitados) \\
\hline
\end{tabular}

Tabla 1. $\mathrm{mL}$ de disolución de $\mathrm{AgNO}_{3}$ gastados en la valoración de las muestras.

Cálculos:

$$
C l^{-} \frac{m g}{L}=\frac{[(A-B)(N)(35450)]}{m L \text { de muestra }}
$$

Donde:

$\mathrm{A}=\mathrm{mL}$ de $\mathrm{AgNO}_{3}$ gastados en la valoración de la muestra

$\mathrm{B}=\mathrm{mL}$ de $\mathrm{AgNO}_{3}$ gastados en la valoración del blanco

$\mathrm{N}=$ normalidad del nitrato de plata igual a 0.014 .

Aplicando la fórmula de determinación de cloruros para el caso del producto (agua destilada) se tiene:

$$
\begin{gathered}
C l^{-}=\frac{[(1.5 m L-3 m L)(0.014)(35450)]}{30 m L} \\
=-24.8 \mathrm{mg} / \mathrm{L}
\end{gathered}
$$

El valor negativo indica que la cantidad de cloruros en el agua destilada es menor en comparación con el agua desmineralizada (blanco), por tal motivo, se evidencia la eficiencia del proceso. En función de ratificar la remoción de sales en el proceso se presenta la prueba de conductividad, vease la Tabla 2.

Se puede observar una remoción significativa de iones en las tres pruebas realizadas y de esta forma se comprueba la calidad del agua obtenida, con el equivalente al $99 \%$ de remoción de sales, presentes en forma de iones, en cada parámetro, además, según la norma NOM-127-SSA1-1994, el agua obtenida se clasifica como potable. 
Tabla 2. Resultados de las pruebas de conductividad, salinidad y solidos totales, efectuadas al agua salada y destilada.

\begin{tabular}{|c|c|c|c|}
\hline & $\begin{array}{c}\begin{array}{c}\text { Conductividad } \\
(\mu \mathrm{s} / \mathrm{cm})\end{array} \\
\end{array}$ & $\begin{array}{c}\text { Salinidad } \\
(\%)\end{array}$ & $\begin{array}{c}\text { Solidos Totales } \\
\text { Disueltos }(\mathrm{mg} / \mathrm{L})\end{array}$ \\
\hline $\begin{array}{c}\text { Agua Cruda (Muestreada de } \\
\text { la Playa) }\end{array}$ & $53050+/-70.7$ & $35.4+/-0.6$ & $33650+/-70.7$ \\
\hline $\begin{array}{l}\text { Agua Destilada (Obtenida del } \\
\text { Prototipo) }\end{array}$ & $281.33+/-0.58$ & 0.1 & $135.16+/-0.21$ \\
\hline
\end{tabular}

En este prototipo se emplea la energía proveniente de una fuente inagotable como es la energía solar lo que la hace amigable al medio ambiente en comparación con métodos de destilación convencionales que emplean la energía eléctrica o combustibles para la generación de calor.

\section{Conclusion}

Se logró obtener agua destilada proveniente del agua de mar mediante el empleo de una energía renovable como fuente de calor mediante un prototipo de fácil elaboración en donde varios de los materiales utilizados son reciclados y de bajo costo, removiendo las sales con un $99 \%$ de efectividad.

\section{References:}

1. Al-Hayeka I, Badran OO. The effect of using different designs of solar stills on water distillation. Desalination 2004;169(2):121-7.

2. Balado, L. (2011). Prototipo de campo de colectores solares cilindroparabólicos para la generación de calor a alta temperatura. http://earchivo.uc3m.es/bitstream/10016/12857/1/PFC\%20Emilio\%2 0Balado\%20Leal.pdf

3. Çengel, Y. A. (2014). Transferencia de calor y masa. McGraw-Hill.

4. IIE. (2017). Mapa de irradiación solar de México. Obtenido del Instituto de Investigaciones Eléctricas: https://www.gob.mx/ineel.

5. NMX-AA-073-SCFI-2011. Análisis de agua -Determinación de cloruros totales en aguas naturales, residuales y residuales tratadasMétodo de prueba. Declaratoria de vigencia publicada en el Diario Oficial de la Federación el 13 de agosto de 2001.

6. Nullvalue (1997). Hay suficientemente agua en el planeta tierra mundo. En El Tiempo en línea, 22 de marzo de 1997. Consultado en $1^{\circ}$. Septiembre de 2016.

7. Saidur, R., Elcevvadi, E., Mekhilef, S., Safari, A., \& Mohammed, H. (2011). An overview of different distillation methods for small scale applications. Renewable and sustainable energy reviews, 4756-4764. 